\title{
Mayor Daan Mogot (1928-1946) Peran Dan Perjuangannya
}

\author{
Rahayu Permana \\ Universitas Indraprasta PGRI \\ Email: rahayupermana877@gmail.com
}

\begin{abstract}
This study aims to determine the biographical study of the figure of Mayor Daan Mogot in Tangerang. Daan Mogot's biographical study approach is very interesting to research, because he was a very important figure during the Indonesian independence revolution in the Tangerang area. The research methodology uses a qualitative approach by collecting data sources relevant to the discussion. The results of research on the role and struggle of Major Daan Mogot include starting his career as a Map Army, BKR, TKR-TRI and becoming the director of the Tangerang Military Academy. Major Daan Mogot's struggle needs to be a good example for today's young generation. So that his heroic values can be an inspiration for the people of Tangerang in particular and in general the Indonesian people.
\end{abstract}

Keywords: Biography, Daan Mogot, His Struggle

\begin{abstract}
Abstrak
Penelitian ini bertujuan untuk mengetahui kajian biografi dari tokoh Mayor Daan Mogot di Tangerang. Pendekatan kajian biografi Daan Mogot sangatlah menarik untuk diteliti, karena beliau merupakan tokoh yang sangat berperan pada masa revolusi kemerdekaan Indonesia di daearah Tangerang. Metodologi penelitian menggunakan pendekatan kualitatf dengan mengumpulkan sumber-sumber data yang relevan dengan bahasan. Hasil penelitian dari peran dan perjuangan Mayor Daan Mogot yakni dimulai karirnya sebagai Tentara Peta, BKR, TKR-TRI dan menjadi direktur Akademi Militer Tangerang. Pada perjuangan Mayor Daan Mogot perlu dijadikan contoh yang baik bagi generasi muda sekarang. Sehingga nilainilai kepahlawanannya dapat menjadi inspirasi bagi masyarakat Tangerang khususnya dan umumnya bangsa Indonesia.
\end{abstract}

Kata kunci: Biografi, Daan Mogot, Perjuangannya

\section{PENDAHULUAN}

Penelitian biografi tokoh lokal dan nasional merupakan hal yang sangat urgen, karena memiliki arti penting dalam suatu peristiwa sejarah sebagai pelaku sejarah. Sejarah suatu daerah sangatlah menarik untuk ditulis secara khusus tentang unsur-unsur dari kebudayaannya, baik itu sosial, politik, ekonomi dan pendidikan. Salah satu penelitian yang bewawasan lokal adalah tokoh yang memiliki peran penting dalam masyarakat lokalnya. Di Tangerang ada tokoh Daan Mogot yang hingga sekarang namanya diabadikan menjadi nama jalan di Tangerang. Daan Mogot adalah pejuang yang perlu diteladani dalam kehidupan perjalanan 


\section{JOURNAL OF SOCIAL SCIENCES \& HUMANITIES "ESTORIA"}

UNIVERSITAS INDRAPRASTA PGRI

karirnya sampai perjuangannya di Tangerang. Dalam hal ini peranan dan aktivitas Daan Mogot yang yang harus dicatat dalam kajian sejarah Tangerang.

Daan Mogot sebagai salah satu tokoh pejuang yang memperjuangkan kemerdekaan Indonesia di wilayah Tangerang. Beliau sudah banyak mengabdikan dirinya untuk tegaknya Indonesia merdeka. Keberanian dan heroisme dari Mayor Daan Mogot sebagai pejuang muda dapatlah menjadi sebuah inspirasi dan sekaligus motivasi bagi generasi, terutama kalangan generasi muda untuk menumbuhkan nilai kepahlawanan dan patriotisme dalam mengisi kemerdekaan Indonesia. Untuk itulah peneliti tertarik terhadap kajian biografi Mayor Daan Mogot untuk diteliti, terutama peranan dan perjuangannya di Tangerang.

\section{METODE PENELITIAN}

Dalam kajian ini akan ditempuh penelitian kualitatif dengan pendekatan metode sejarah yang memiliki empat tingkatan kegiatan, yaitu heuristik merupakan langkah pengumpulan data yang kemudian sumber terkumpul diuji melalui kritik sumber. Data teruji ditafsirkan informasi yang terdapat didalamnya melalui interpretasi, dan tahap selanjutnya historiografi yakni disusun kisah dan uraian keseluruhan sejarahnya (Sulasman, 2014).

\section{HASIL PENELITIAN DAN PEMBAHASAN}

\section{Biografi Mayor Daan Mogot}

Daan Mogot yang memiliki nama asli Elias Daniel Mogot lahir dari pasangan Nicolaas Mogot (ayah) dan Emilia Mien Inkiriwang (ibu). Lahir di Manado, Sulawesi Utara pada tanggal 28 Desember 1928. Ia merupakan anak kelima dari tujuh bersaudara. Ayahnya adalah seorang Hakim Besar Ratahan. Ini artinya Daan Mogot berasal dari keluarga yang memiliki jiwa pemimpin. Sedikit banyak ia mewarisi darah pemimpin dari sang ayah yang seorang Hakim Besar Ratahan(Permana \& Erni, 2019).

Sebagai anak seorang pejabat pemerintahan, Daan Mogot tentu bisa bersekolah di ELS (Europeesche Lagere School). Sekolah yang 


\section{JOURNAL OF SOCIAL SCIENCES \& HUMANITIES “ESTORIA” UNIVERSITAS INDRAPRASTA PGRI}

diperuntukkan bagi anak-anak Belanda atau Eropa atau yang disamakan kedudukannya. Lulus dari ELS bisa melanjutkan ke MULO (SMP) atau AMS (SMA). Maka ketika usia Daan Mogot 14 tahun, ia terpilih untuk mengikuti latihan Seinen Dojo (pelatihan pemuda). Pelatihan militer di masa pendudukan Jepang. Latihannya lebih keras dan lebih militer. Itulah awal karir Daan Mogot di militer. Bahkan karena kecerdasannya ia terpilih menjadi anggota PETA di usia yang masih muda. Bahkan termasuk anggota yang langka. Karena kebanyakan anggota PETA adalah orang-orang Jawa. Orang Manado termasuk langka (Permana \& Erni, 2019).

\section{Peran Mayor Daan Mogot Dimasa Revolusi Kemerdekaan Sebagai Seinen Dojo}

Pembentukan Seinen Dojo selain mempunyai kepentingan seperti yang tercantum diatas (sebagai media untuk menguji kemampuan pemuda-pemuda Indonesia dalam masalah kemiliteran juga mempunyai tujuan lain yang sifatnyatersembunyi. Kepentingan ini erat dengan rencana Jepang dalam mempersiapkan tentara keenambelas guna kepentingandilancarkannya operasi militer terhadap Australia atau mempersiapkan diri untuk menghadapi serbuan pihak sekutu yang akan datang menyerbu dari Australia. Tangerang Seinen Dojo menempati suatu bangunan yang berada dalam komplek gedung di daerah Batuceper, dalam wilayah kabupaten Tangerang (Notosusanto, 1979)

Pendidikan angkatan pertama berakhir pada bulan Juni 1943 dengan hasil cukup baik, para lulusannya antara lain Daan Mogot, Kemal Idris, Julkifli Lubis, Yono Suwoyo, dan Supriyadi. Keberhasilan pendidikan angkatan pertama mendorong panglima tentara ke-16 dan Beppan (Bagian Khusus Staf umum) untuk membuka pendidikan angkatan berikutnya (Sunda, 2004).

Para siswa yang telah lulus dari angkatan pertama mereka tidak diberikan tanda pangkat kemiliteran seperti tanda pangkat sekolah perwira PETA di Bogor. alumnus angkatan pertama dari Tangerang Seinen Dojo oleh Beppan juga diberi wewenang untuk melakukan pengujian terhadap kader-kader calon siswa PETA, selain itu setelah sekolah perwira 
PETA berjalan, alumnus dari Seinen Dojo angkatan pertama ini ditugaskan untuk menjadi instruktur pembantu pada sekolah perwira tersebut (Susanto, 1996).

\section{Sebagai Tantara PETA}

Pembentukan PETA oleh Jepang dimaksudkan untuk dipergunakan mempertahankan wilayah Jawa terhadap serangan tentara sekutu. Sistem pertahanan yang dipergunakan Jepang yakni: Pertahanan disusun dengan tiga lini. Lini terdepan, dipantai, terdiri atas kesatuan-kesatuan Indonesia. Dengan demikian merekalah yang akan menerima pukulan pertama dari pihak sekutu dalam serangan balasannya. Lini kedua terdapat pada dataran tinggi di tengah. Lini ketiga terdapat digununggunung dimana kelompok-kelompok tentara Jepang dan Indonesia akan melaksanakan perang gerilya (Siliwangi, 1968).

Daan Mogot adalah Sebagai Anggota Pembela Tanah Air (PETA) angkatan ke-1 (1943). Di usianya yang 14 tahun (tahun 1943) Daan Mogot masuk PETA (Pembela Tanah Air) yaitu organisasi militer pribumi bentukan Jepang di Jawa, walaupun sebenarnya ia tak memenuhi syarat karena usianya belum genap 18 tahun (PETA, n.d.).

Oleh prestasinya yang luar biasa, ia diangkat menjadi pelatih PETA di Bali. Setelah pelatihan PETA di Bogor, Daan Mogot terpilih menjadi Shodancho (Komandan Peleton) PETA yang ditempatkan di Bali (19431944). Setelah dilantik menjadi perwira PETA, Daan Mogot, Zulkifli Lubis dan Kemal Idris bersama beberapa perwira PETA lainnya mendirikan sekolah untuk melatih para calon anggota PETA di Bali (25 Januari 1946: Palagan Lengkong, Meninggalnya Daan Mogot Di Serpong, 2013).

\section{Menjadi Badan Keamanan Rakyat (BKR)}

Badan Keamanan Rakyat (BKR) yang dinyatakan resmi berdiri tanggal 23 Agustus 1945, tapi baru dapat direalisir pada tanggal 30 Agustus 1945. Organisasi BKR ditingkat pusat diketuai oleh Mr. Kasman Singodimedjo seorang mantan Daidancho PETA, sedangkan yang ada di daerah langsung dibawahkan oleh KNI Daerah masing-masing dan secara struktural tidak dibawahkan BKR Pusat. Dengan berdirinya BKR, maka semua mantan anggota PETA, Heiho, KNIL dan para pemuda umumnya 


\section{JOURNAL OF SOCIAL SCIENCES \& HUMANITIES "ESTORIA" UNIVERSITAS INDRAPRASTA PGRI}

dimintakan untuk menggabungkan dirinya didalam BKR ini, sehingga BKR menjadi wadah dari pemuda-pemuda militan dan revolusioner (Saleh, 1992).

Daan Mogot bergabung dengan BKR dan mendapat pangkat Mayor. Ini hal yang menarik, mengingat usia Daan Mogot saat itu baru 16 tahun. Mayor Daan Mogot bertugas di bawah pimpinan yang bernama Letnan Kolonel Moeffreni Moe'min, seorang mantan Daidanco PETA dari Daidan I Jakarta, Pasukan yang menaungi wilayah Karesidenan Jakarta bermarkas di Jalan Cilacap No. 5. Sejumlah perwira ex-PETA yang bergabung di pasukan tersebut, antara lain Singgih, Daan Jahja, Kemal Idris, Daan Mogot, Islam Salim, Jopie Bolang, Oetardjo, Sadikin (Resimen Cikampek), Darsono (Resimen Cikampek), dan lain-lain (Saleh, 1992).

\section{Sebagai Tentara Keamanan Rakyat}

Setelah satu setengah bulan merdeka, maka pada tanggal 5 Oktober 1945 BKR diubah namanya menjadi Tentara keamanan Rakyat (TKR). Pemerintah mengeluarkan maklumat untuk membentuk TKR, tentara kebangsaan yang resmi. Dengan lahirnya TKR, amak BKR dengan sendirnya dilebur didalamnya, tanpa didahului oleh suatu keputusan tertulis apa-apa mengenai status dan eksitensi BKR. Dengan demikian nama BKR otomatis hilang dan diganti dengan nama TKR (Saleh, 1992).

Karena melihat situasi perjuangan di Jakarta dari hari ke hari terus menerus bertambah gawat. NICA bertambah membabi buta dengan terornya. Untuk menghadapi tantangan perjuangan yang semakin berat itu, maka pada tanggal 5 oktober 1945 Presiden Sukarno telah mendekritkan berdirinya TKR (Tentara Keamanan Rakyat). Ini adalah merupakan suatu peningkatan dari BKR. Daan Mogot menjadi salah satu pemimpin TKR, dengan pangkat Mayor. Saat itu, usia Daan Mogot masih belum genap 18 tahun. Bersama Kemal Idris, Daan Jahja, Jopie Bolang, dan Islam Salim bergabung dengan Resimen IV TKR di Tangerang (Madjiah, 1986).

\section{Mayor Daan Mogot dan Pendirian Akademi Militer Tangerang}

Kepedulian Daan Mogot atas nasib bangsa ini yang ia utarakan kepada sepupunya Alex Kawilarang, bahwa ia ingin melatih perwira 


\section{JOURNAL OF SOCIAL SCIENCES \& HUMANITIES "ESTORIA" UNIVERSITAS INDRAPRASTA PGRI}

Republik mulai terwujud seiring berjalannya waktu. Inilah sejarah dan riwayat bagaimana Akademi Militer Tangerang berdiri. Maka atas prakarsa beberapa orang perwira, direcanakan pembentukan suatu pendidikan perwira dimana dalam waktu yang singkat mungkin sudah dapat mencetak perwira-perwira yang dapat ditugaskan sebagai komandan seksi (pleton) khususnya untuk ditempatkan di Resimen TKR Tangerang dan umumnya TKR Jakarta Raya dan Jawa Barat. Para perwira yang memprakarsai pembentukan akademik militer itu antara lain: Letkol Singgih, Letkol Suroto Kunto, Mayor Daan Yahya, Mayor Daan Mogot, Kapten Kemal Idris, Kapten Taswin, Lettu Subiyanto Joyohadikusumo dan Lettu Sutopo (Madjiah, 1986).

Dapat di jelaskan di sini bahwa pada tanggal 10 Nopember diumumkanlah mengenai pembukaan akademik militer. Pada waktu membaca berita tersebut disurat kabar, masyarakat sangat antusias menanggapinya. Karena pengumuman tersebut sangat menarik perhatian baik tujuannya maupun gaya bahasa dan isinya. Pada tanggal 15 Nopember 1945 mereka diwajibkan untuk datang ke Jl. Prapatan 10. Jakarta (tepatnya di Asrama Mahasiswa Kedokteran), untuk mengikuti seleksi kesehatan, pengetahuan umum dal lain-lain. Tes ini diselenggarakan oleh TKR Jakarta (Saleh, 1992).

Asrama Mahasiswa kedokteran sebenarnya tidak Jauh lokasinya dari tangsi Batalion sepuluh di Senen yang terkenal angker, tapi karena para mahasiswa kedokteran yang menghuni asrama itu pernah mendapat latihan kemiliteran zaman Jepang dan merupakan para pejuang yang sudah aktif sejak proklamasi kemerdekaan serta kini memiliki sejumlah senjata api hasil curian dari kesatrian PETA, maka keamanan gedung asrama tersebut dapat diandalkan pada mereka (Saleh, 1992).

Akademi Militer Tangerang secara organisasitorisnya berada dibawah Resimen IV Tangerang pimpinan Letkol Kolonel Singgih. Mayor Daan Mogot menjadi direkturnya dibantu oleh pada kepala seksi. Tujuan pendidikan di Akademi Militer Tangerang adalah untuk menghasilkan komandan seksi yang cakap, tegar dan berjiwa patriotik. Untuk mencapai tujuan tersebut tentunya dibutuhkan waktu yang cukup lama, tetapi 


\section{JOURNAL OF SOCIAL SCIENCES \& HUMANITIES “ESTORIA” UNIVERSITAS INDRAPRASTA PGRI}

karena situasi dalam keadaan darurat, maka lama waktu pendidikan hanya 6 bulan saja. Dapatlah dijelaskan peranan Mayor Daan Mogot selaku pimpinan MAT sangatlah besar. Pertama mengirimkan anggotanya untuk pengawalan bahan makanan untuk RAPWI (Rehabilitation Alied Prisoners of War and Internees) dan membawa tugas untuk menguruskan APWI yang banyak terdapat di pulau Jawa. Dalam rangka kerjasama Pemerintah RI dengan sekutu, para taruna militer akademi Tangerang, sesuai dengan perintah perdana Menteri Sultan Syahrir, dalam beberapa hari mendatang ditugaskan untuk mengawal kereta api yang mengangkut bahan makanan untuk RAPWI dari Jakarta ke Bandung. Detasemen Istimewa dari Militer Adakemi Tangerang, untuk mengawal suplai Inggris maupun untuk mengawal tawanan-tawanan perang yang diurus oleh RAPWI (Siliwangi, 1968).

Kedua, memerintahkan Perwira MAT untuk mengawal pameran lukisan di Jakarta. Pada tanggal 27 Desember 1945, dengan bertempat di gedung sekolah kedokteran tinggi Jakarta, diselenggarakan suatu pameran lukisan yang dikunjungi oleh Presiden RI bersama Jenderal Christison. Panglima Tentara Sekutu di Jawa. Tugas pengabdian itu dapat dilaksanakan dengan sempurna dan sangatlah memuaskan.

Ketiga, penumpasan pemberontakan ubel-ubel, hanya beberapa bulan saja pemerintahan Dewan itu dapat berkuasa di Tangerang, karena pada tanggal 7 Januari 1946 TKR yang waktu itu sudah berganti nama menjadi TRI, diperintahkan untuk mengambil tindakan menumpas pemberontakan tersebut (Siliwangi, 1968). Melihat situasi yang semakin memburuk itu, maka pada tanggal 14 Januari 1946, TKR Resimen IV dibawah pimpinan Letnan Kolonel Singgih, dengan dibantu oleh para taruna MAT dibawah pimpinan Mayor Daan Mogot, bertindak tegas, mengembalikan kekuasaan Pemerintah RI di Tangerang. Dalam operasi penumpasan itu, tidak sedikit senjata yang berhasil dirampas oleh para taruna MAT. Dengan demikian, maka keamanan di Tangerang pulih seperti sedia kala, sehingga nama MAT dimata rakyat semakin meningkat (Siliwangi, 1968). 


\section{JOURNAL OF SOCIAL SCIENCES \& HUMANITIES "ESTORIA" UNIVERSITAS INDRAPRASTA PGRI}

Keempat, memimpin pelucutan senjata milik Jepang di Lengkong. Gerakan operasi ke Lengkong dilaksanakan pada tanggal 25 Januari 1946 itu juga. Tim yang terdiri dari Letkol Singgih, Mayor Daan Mogot, dan Kapten Enjon yang bertujuan agar pelucutan senjata berjalan dengan damai (Kartodirdjo, n.d.). Pada mulanya rencana Daan Mogot berjalan lancar, pihak Jepang nampaknya setuju untuk menyerahkan senjata. Sejumlah senjata dapat diperoleh dan dikumpulkan (Siliwangi, 1968). Namun kemudian penyamaran mereka diketahui oleh Kapten Abe. Ketika salah seorang bekas serdadu India mengambil sepucuk senjata Jepang dari tumpukan untuk diamat-amati karena ia baru kali itu melihat senjata semacam itu. Ia mulai mengutik-utik senjata itu. Entah apa sebabnya, tiba-tiba senjata itu Meletus (Madjiah, 1986).

Letusan itu seketika itu juga mengagalkan secara total diplomasi Daan Mogot. Begitu pihak Jepang mendengar letusan itu, mereka menjadi curiga dan menganggap letusan itu sebagai kode tanda dimulainya penyerangan oleh pihak TRI. Maka segera mereka mendahului melepaskan tembakan, menyerang pasukan Daan Mogot. Pihak Jepang yang menduga bahwa mereka telah dijebak, segera pula melepaskan tembakan-tembakan gencar yang ditunjukkan kepada para taruna MAT. Mayor Daan Mogot langsung berlari keluar meninggalkan meja perundingan dan berusaha menghentikan pertempuran tidak berhasil, ia berteriak agar peristiwa tersebut segera dihentikan. Namun, peringatan dari Mayor Daan Mogot tersebut tidak dihiraukan oleh kedua belah pihak (Sunda, 2004). Dalam pertempuran yang tidak seimbang ini Mayor Daan Mogot dan 37 taruna gugur, sedangkan 35 orang tertawan(Kartodirdjo, n.d.).

Pada tanggal 25 Januari 1946 Daan Mogot gugur pada waktu memimpin pelucutan senjata Jepang di Lengkong. Semua yang meninggal dalam peristiwa Lengkong dikebumikan kembali pada tanggal 29 Januari 1946 di kompleks markas Resimen IV Tangerang (sekarang makan Pahlawan Taruna di Jalan Daan Mogot) (Sunda, 2004). 


\section{JOURNAL OF SOCIAL SCIENCES \& HUMANITIES "ESTORIA" UNIVERSITAS INDRAPRASTA PGRI}

\section{KESIMPULAN}

Dari uraian pembahasan diatas dapatlah disimpulkan bahwa Mayor Daan Mogot merupakan sosok pahlawan yang patut dicontoh dalam perjuangannya. Beliau walaupun usianya masih terbilang muda, namun semangatnya patutlah diacungkan jempol. Keberanian dan kegigihan yang dimiliki oleh Mayor Daan Mogot baik sebagai tantara Peta masa pendudukan Jepang, pada masa kemerdekaan Indonesia sebagai BKR, TKR-TRI serta sebagai Direktur Akademi Militer Tangerang. Peran beliau di masa kemerdekaan Indonesia seperti yang sudah dijelaskan diatas, sangatlah penting untuk selalu dikenang terutama oleh masyarakat Tangerang khususnya dan umumnya untuk Indonesia.

\section{DAFTAR PUSTAKA}

25 Januari 1946: Palagan Lengkong, Meninggalnya Daan Mogot di Serpong. (2013). Kabartangsel.Com. https://kabartangsel.com/25januari-1946-palagan-lengkong-meninggalnya-daan-mogot-diserpong/

Kartodirdjo, S. (n.d.). Marwati Djoened Poesponegoro, dan Nugroho Notosusanto. Sejarah Nasional Indonesia Jilid, 6.

Madjiah, M. (1986). Kisah seorang dokter gerilya dalam revolusi kemerdekaan di Banten. Penerbit Sinar Harapan.

Notosusanto, N. (1979). Tentara Peta pada jaman pendudukan jepang di Indonesia. Gramedia.

Permana, R., \& Erni, D. (2019). Sebuah Cerita Sejarah. Disbudpar.

PETA, Y. (n.d.). Pimpinan Umum Tentara Pembela Tanah Air (Y. P. T. Air (Ed.)).

Saleh, R. H. A. (1992). Dari Jakarta Kembali Ke Jakarta. Pemerintah Daerah Khusus Ibukota Jakarta, Dinas Museum dan Sejarah.

Siliwangi, D. S. M. K. V. I. (1968). Siliwangi dari Masa ke Masa. In Djakarta: Fakta Mahjuma.

Sulasman. (2014). Metodologi Penelitian Sejarah. Pustaka Setia.

Sunda, T. P. S. (2004). Sejarah Kabupaten Tanggerang. Pemerintah Kabupaten Tanggerang.

Susanto, F. (1996). Tangerang Seinen Dojo Uji Coba militer Jepang Terhadap Pemuda Indonesia 1943. Skripsi, Fakultas Ilmu. 